\title{
Extended Kalman Filter for Sensorless Fault Tolerant Control of PMSM with Stator Resistance Estimation
}

\author{
Mongi Moujahed ${ }^{1}$, Bilel Touaiti ${ }^{2}$, Hechmi Benazza $^{3}$, Mohamed Jemli ${ }^{4}$, Mohamed Boussak ${ }^{5}$ \\ 1,2,3,4 Departement of Electrical Engineering, National Higher School of Engineering Tunisia University, Tunisia \\ ${ }^{5}$ Departement of Electrical Engineering, Central school of Marseille, France
}

\begin{tabular}{l} 
Article Info \\
\hline Article history: \\
Received Dec 15, 2017 \\
Revised Feb 17, 2018 \\
Accepted Apr 10, 2018 \\
\hline
\end{tabular}

Keyword:

Extended kalman filter (EKF)

Fault tolerant control (FTC)

Fault tolerant inverter

Permanent magnet synchronous

motors (PMSM)

Stator resistance estimation

\section{Corresponding Author:}

Mongi Moujahed,

Departement of Electrical Enfineering

National Higher School of Engineering Tunis University,

05 Street Taha Hussein, Tunis Tunisia

Email: mongi.moujahed@isetkr.rnu.tn

\begin{abstract}
This paper aims to provide a high performance sensorless control based on an Extended Kalman Filter (EKF) applied to fault-tolerant PMSM drive system with stator-resistance estimation. It proposes a fast method of fault switches detection in the power converters. The considered drive is composed of three phases PMSM and a four leg three phase's inverter when the fourth is the redundant leg. After a short-switch fault occurrence, the redundant leg replaces the faulty leg. The simulation results verify that the proposed control method and the fault tolerant inverter ensure the high reliability and continuously operation of the sensorless vector control PMSM system under inverter fault.
\end{abstract}

Copyright $@ 2018$ Institute of Advanced Engineering and Science. All rights reserved.

\section{INTRODUCTION}

The Due to its high efficiency, high ratio of torque to weight, high power factor, faster response and rugged construction, PMSM is the most widely used for high performance variable speed in many industry applications [1], [2], [3]. Nowadays, sensorless control is adopted in many industrial applications for reasons of robustness, cost, cabling and reliability. A number of sensorless control methods have been proposed in the literature for PMSM [4], [5], [6]. In this paper a sensorless fault tolerant control based on Extended Kalman Filter (EKF) with stator resistance to reduce hardware complexity and lower cost, reduce size of the drives, elimination of the sensor cable, better noise immunity, increase reliability, and less maintenance requirements is presented [7], [8]

A new technique based on MRAS, which permits to estimate the stator resistance for sensorless vector fault tolerant control of PMSM is presented. Stability analysis and design of the MRAS estimators have been performed for a PMSM error model in a synchronous rotating reference frame fixed to the estimated d-q axis stator currents. The adaptation mechanism is done by using the error between the measured and the estimated stator currents. The stabilities of stator resistance estimator are proven via the Popov's hyperstability theory.

For these applications, continuously operation, high reliability and performance are firmly required. However, any faults, especially inverter faults, will affect or even damage the drive. Therefore, fault tolerant strategy for the drive is needed to minimize the consequent damage and keep the system operating continuously with high performance in case the fault occurrence [9], [10]. 
The standard three-phase six-switch inverter doesn't have fault tolerant capability; therefore some inverter faults and modified versions of the standard inverter bridge configuration combined with different control method have been studied and compared to create systems that are tolerant to one or more types of faults to ensure the operation continuity of the drive systems [11].

Several fault tolerant topologies have already been proposed [12], [13], and it's noticeable that the drive composed of a three PMSM and a four-leg inverter with the fourth leg is redundant; has the ability to cope correctly almost the electrical faults, at least one leg fault [14].

Therefore, this paper is organized in such a way: The theory of PMSM is first presented in Sect. 2, The remaining sections of the paper are arranged as follows. Section 3 presents the Extended Kalman Filter, Section 4 presents the stator resistance estimation, Section 5 explains the fault-tolerant control (FTC). Section 6 presents the topology of the fault-tolerant inverter. Section 7 explains the principle of the fault- tolerant vector field-oriented control presented in this paper. Section 8 is reserved for the simulation results, and Section 9 conclude the paper.

\section{PMSM MODEL}

The d-q axis stator flux linkages can be expressed as follows.

$\varphi_{d}=L_{d} i_{d}+K_{e}$

$\varphi_{q}=L_{d} i_{q}$

where: $K_{e}=\sqrt{\frac{3}{2}} \hat{\varphi}_{m}$

By using (1) and (2), electromagnetic torque as a function of permanent magnet flux linkage stator currents can be written as:

$$
\begin{aligned}
& T_{e}=N_{p}\left(\varphi_{d} i_{q}-\varphi_{q} i_{d}\right) \\
& T_{e}=N_{p}\left(K_{e} i_{q}+\left(L_{d}-L_{q}\right) i_{d} i_{q}\right)
\end{aligned}
$$

By using (1) and (2) the model of the PMSM expressed in the d-q synchronously rotating reference frame is given by:

$$
\left[\begin{array}{l}
V_{d} \\
V_{q}
\end{array}\right]=\left[\begin{array}{cc}
R_{s}+\frac{d}{d t} L_{d} & -\omega_{r} L_{q} \\
\omega_{r} L_{d} & R_{s}+\frac{d}{d t} L_{q}
\end{array}\right]\left[\begin{array}{c}
i_{d} \\
i_{q}
\end{array}\right]+K_{e} \omega_{r}\left[\begin{array}{l}
0 \\
1
\end{array}\right]
$$

On the other hand, the mechanical equation of the motor is:

$$
T_{e}-T_{l}=J \frac{d \Omega}{d t}+f \Omega
$$

where: $\omega_{r}=N_{p} \Omega$ follows:

By using (1), (2), (3), (4), (5) and (6) the dynamic model of the PMSM in d-q frame is expressed as

$$
\frac{d}{d t}\left[\begin{array}{c}
i_{d} \\
i_{q} \\
\omega_{r} \\
\theta_{r}
\end{array}\right]=\left[\begin{array}{cccc}
-\frac{R_{s}}{L_{d}} & \frac{L_{q}}{L_{d}} \omega_{r} & 0 & 0 \\
-\frac{L_{d}}{L_{q}} \omega_{r} & -\frac{R_{s}}{L_{q}} & -\frac{K_{e}}{L_{q}} & 0 \\
N_{p}^{2} \frac{L_{d}-L_{q}}{J} & N_{p}^{2} \frac{K_{e}}{J} & -\frac{f}{J} & 0 \\
0 & 0 & 1 & 0
\end{array}\right]\left[\begin{array}{c}
i_{d} \\
i_{q} \\
\omega_{r} \\
\theta_{r}
\end{array}\right]+\left[\begin{array}{ccc}
1 & 0 & 0 \\
L_{d} & 1 & 0 \\
0 & \frac{L_{q}}{2} & N_{p} \\
0 & 0 & -\frac{J}{J} \\
0 & 0 & 0
\end{array}\right]\left[\begin{array}{c}
V_{d} \\
V_{q} \\
T_{l}
\end{array}\right]
$$


By using Equation (7) the state space model of the PMSM expressed in the $\alpha-\beta$ stationary reference frame is described by:

$$
\frac{d}{d t}\left[\begin{array}{c}
i_{\alpha} \\
i_{\beta} \\
\omega_{r} \\
\theta_{r}
\end{array}\right]=\left[\begin{array}{llll}
a_{11} & a_{12} & a_{13} & a_{14} \\
a_{21} & a_{22} & a_{23} & a_{24} \\
a_{31} & a_{32} & a_{33} & a_{34} \\
a_{41} & a_{42} & a_{43} & a_{44}
\end{array}\right]\left[\begin{array}{c}
i_{\alpha} \\
i_{\beta} \\
\omega_{r} \\
\theta_{r}
\end{array}\right]+\left[\begin{array}{lll}
b_{11} & b_{12} & b_{13} \\
b_{21} & b_{22} & b_{23} \\
b_{31} & b_{32} & b_{33} \\
b_{41} & b_{42} & b_{43}
\end{array}\right]\left[\begin{array}{c}
v_{\alpha} \\
v_{\beta} \\
T_{l}
\end{array}\right]
$$

where:

$$
\begin{aligned}
& a_{11}=-\frac{R_{s}}{2 L_{\Pi}}\left(L_{\Sigma}-L_{\Delta} \cos 2 \theta_{r}\right)+\frac{\omega_{r} L_{\Sigma}}{2 L_{\Pi}} L_{\Delta} \sin 2 \theta_{r} ; a_{12}=\frac{\omega_{r} L_{\Delta}}{2 L_{\Pi}}\left(L_{\Delta}-L_{\Sigma} \cos 2 \theta_{r}\right)+\frac{R_{s}}{2 L_{\Pi}} L_{\Delta} \sin 2 \theta_{r} ; \\
& ; a_{14}=0 ; a_{21}=-\frac{\omega_{r} L_{\Delta}}{2 L_{\Pi}}\left(L_{\Delta}+L_{\Sigma} \cos 2 \theta_{r}\right)+\frac{R_{s}}{2 L_{\Pi}} L_{\Delta} \sin 2 \theta_{r} ; \\
& a_{22}=-\frac{R_{S}}{2 L_{\Pi}}\left(L_{\Sigma}+L_{\Delta} \cos 2 \theta_{r}\right)+\frac{\omega_{r}}{2 L_{\Pi}} L_{\Sigma} L_{\Delta} \sin 2 \theta_{r} a_{23}=-\frac{K_{e}}{L_{q}} \cos \theta_{r} ; a_{24}=0 ; \\
& a_{31}=-\frac{N_{p}^{2}}{J}\left(K_{e} \sin \theta_{r}+\frac{L_{\Delta}}{2}\left(i_{\alpha} \sin 2 \theta_{r}\right)\right) ; a_{32}=\frac{N_{p}^{2}}{J}\left(K_{e} \cos \theta_{r}+\frac{L_{\Delta}}{2}\left(i_{\beta} \sin 2 \theta_{r}+2 i_{\alpha} \cos 2 \theta_{r}\right)\right) ; \\
& a_{33}=-\frac{f}{J} ; a_{34}=0 ; a_{41}=0 ; a_{42}=0 ; a_{43}=1 ; a_{44}=0 ; b_{11}=\frac{1}{2 L_{\Pi}}\left(L_{\Sigma}-L_{\Delta} \cos 2 \theta_{r}\right) ; \\
& b_{12}=-\frac{L_{\Delta}}{2 L_{\Pi}} \sin 2 \theta_{r} ; \\
& b_{13}=0 ; b_{21}=-\frac{L_{\Delta}}{2 L_{\Pi}} \sin 2 \theta_{r} ; b_{22}=\frac{1}{2 L_{\Pi}}\left(L_{\Sigma}+L_{\Delta} \cos 2 \theta_{r}\right) ; b_{23}=0 ; b_{31}=0 ; b_{32}=0 ; b_{33}=-\frac{N_{p}}{J} ; \\
& b_{41}=0 ; b_{42}=0 ; b_{43}=0 ; L_{\Sigma}=L_{d}+L_{q} ; L_{\Delta}=L_{d}-L_{q} ; L_{\Pi}=L_{d} \times L_{q} ;
\end{aligned}
$$

This state space model (8) is used by EKF observer to estimate both rotor position and speed.

\section{EXTENDED KALMAN FILTER}

The EKF is mostly used for tracking and estimating nonlinear systems because of it's of the salientpole PMSM, EKF is used for the estimation of the speed and rotor position. The speed and the rotor position being the two estimated magnitudes are with the motor current both constitute the state vector. While the motor currents are the only observable magnitudes that constitute the output vector. For the implementation of an EKF to sensor-less PMSM drive, the choice of the two axis reference frame is necessary. The perfect case is to use d-q synchronously rotating reference frame. This solution is not compatible for PMSM sensorless speed control because the input vector (currents and voltages) of the estimator are dependent on the rotor position. We can observe that an error of estimation in the initial position of the rotor can have serious repercussions by inducing error in the progress of the EKF with regard to the real system. We seek to preserve the PMSM control in the rotor reference frame. The speed and the position are estimated by using only measurements of the stator voltages and currents [15], [16], [17] The EKF based observer uses the motor model with quantities in the fixed reference frame $\alpha-\beta$ attached to the stator frame and are therefore independent of the rotor position. The nonlinear dynamic state model of the IPMSM in a stationary reference frame is described by the following expressions:

$$
\left\{\begin{array}{c}
\frac{d}{d t}[X]=[A][X]+[B][U] \\
{[Y]=[C][X]}
\end{array}\right.
$$


The matrix elements of $\mathrm{A}$ and $\mathrm{B}$ are given in equation 8. The two stator currents, the electrical speed and position are used as system state variables.

The EKF algorithm should be calculated by the dynamic state model given by (9) which is to be expressed in a discrete state model. The discrete state model is described by the following expressions:

$$
\left\{\begin{array}{c}
\frac{d}{d t} x(t)=f[x(t), u(t), t]+G(t) v(t) \\
y\left(t_{i}\right)=h\left[x\left(t_{i}\right), t_{i}\right]+w\left(t_{i}\right)
\end{array}\right.
$$

Where $\mathrm{x}(\mathrm{t})$ is the state vector, $\mathrm{y}(\mathrm{ti})$ is the output vector of the discrete state model defined as the measurement signals.

The output vector variables are defined as:

$$
\begin{aligned}
& y\left(t_{i}\right)=\left[\begin{array}{c}
i_{\alpha}(t) \\
i_{\beta}(t)
\end{array}\right] \\
& h\left[x\left(t_{i}\right), t_{i}\right]=\left[\begin{array}{c}
i_{\alpha}\left(t_{i}\right) \\
i_{\beta}\left(t_{i}\right)
\end{array}\right]
\end{aligned}
$$

The state vector variables are defined as

$$
\begin{aligned}
& x_{k}=\left[\begin{array}{llll}
i_{\alpha} & i_{\beta} & \omega_{r} & \theta_{r}
\end{array}\right]_{k}^{T} \\
& y_{k}=\left[\begin{array}{ll}
i_{\alpha} & i_{\beta}
\end{array}\right]_{k}^{T}
\end{aligned}
$$

$\mathrm{f}[\mathrm{x}(\mathrm{t}), \mathrm{u}(\mathrm{t}), \mathrm{t}]$ is given in (9), The command vector $\mathrm{u}$ is $u(t)=\left[\begin{array}{ll}V_{\alpha} & V_{\beta}\end{array}\right]^{T}$ and $H_{k+1}=\left[\begin{array}{llll}1 & 0 & 0 & 0 \\ 0 & 1 & 0 & 0\end{array}\right]$

$$
[L]=\left[\begin{array}{ccc}
l_{s}+L_{0}+L_{2} \cos 2 \theta_{r} & -\frac{L_{0}}{2}+L_{2} \cos \left(2 \theta_{r}-\frac{2 \pi}{3}\right) & -\frac{L_{0}}{2}+L_{2} \cos \left(2 \theta_{r}+\frac{2 \pi}{3}\right) \\
-\frac{L_{0}}{2}+L_{2} \cos \left(2 \theta_{r}-\frac{2 \pi}{3}\right) & l_{s}+L_{0}+L_{2} \cos \left(2 \theta_{r}+\frac{2 \pi}{3}\right) & -\frac{L_{0}}{2}+L_{2} \cos \left(2 \theta_{r}\right) \\
-\frac{L_{0}}{2}+L_{2} \cos \left(2 \theta_{r}+\frac{2 \pi}{3}\right) & -\frac{L_{0}}{2}+L_{2} \cos \left(2 \theta_{r}\right) & l_{s}+L_{0}+L_{2} \cos \left(2 \theta_{r}+\frac{2 \pi}{3}\right)
\end{array}\right]
$$

The choice of initial values for matrixes $\mathrm{P}, \mathrm{Q}$ and $\mathrm{R}$ is very important. The parameter of the PMSM used for simulation is given in Table. 1

Table 1. PMSM Parameters

\begin{tabular}{ccc}
\hline Parameters & \multicolumn{2}{c}{ Specifications } \\
\hline $\mathrm{Rs}=0.5 \Omega$ & Rated power & $1.57 \mathrm{~kW}$ \\
$\mathrm{Ld}=4.2 \mathrm{mH}$ & Rated voltage & $400 \mathrm{~V}$ \\
$\mathrm{Lq}=3.6 \mathrm{mH}$ & Rated current & $4.2 \mathrm{~A}$ \\
$\mathrm{Kt}=0.91$ & Vdc & $540 \mathrm{~V}$ \\
$\mathrm{~K}=0.2275 \mathrm{~V} . \mathrm{s} / \mathrm{rad}$ & Number of pole pairs & 4 \\
$\mathrm{~J}=0.00072 \mathrm{Kg} . \mathrm{m}^{2}$ & Rated speed & $3000 \mathrm{rpm}$ \\
$\mathrm{F}=10-6 \mathrm{Nm} . / \mathrm{rad}$ & Rated torque & $4.1 \mathrm{Nm}$ \\
\hline
\end{tabular}

The EKF is a mathematical tool for estimating the states of dynamic nonlinear systems. The nonlinear state space equations of the motor model are written in the following continuous form: 


$$
\left\{\begin{array}{c}
x(t)=f[x(t), u(t), t]+G(t) v(t) \\
y\left(t_{i}\right)=h\left[x\left(t_{i}\right), t_{i}\right]+w(t)
\end{array}\right.
$$

Where the initial state vector $\mathrm{x}(\mathrm{t} 0)$ is modeled as a Gaussian-random vector with mean $\mathrm{x}_{0}$ and covariance $\mathrm{P} 0, \mathrm{u}(\mathrm{t})$ is the deterministic control input vector, $\mathrm{v}(\mathrm{t})$ is zero-mean Gaussian noise matrix of state model which is independent of $x(t 0)$ with a covariance matrix $Q(t), W(t)$ is a zero-mean white Gaussian noise matrix of output model with a covariance $R(t), G(t)$ is the weighting matrix of noise, $y$ the output vector and $\mathrm{u}$ the control matrix. The filter has a predictor-corrector structure as follows (superscripts $\mathrm{k}$ and $\mathrm{k}+1$ refer to the time before and after the measurements have been processed). The discrete form of EKF algorithm can be summarized as follows.

\subsection{Prediction of States}

$$
\hat{x}_{k+1 / k}=\hat{x}_{k / k}+\int_{t_{k}}^{t_{k+1}} f\left[\hat{x}_{t / t_{k}}, u(t), t\right] d t
$$

\subsection{Prediction of the Covariance Matrix of States}

$$
\begin{aligned}
& P_{k+1 / k}=\varphi(k+1, k) P_{(k-1) / k} \varphi^{T}(k+1, k)+Q_{d}(k) \\
& \varphi(k+1, k)=e^{\left(F[k] T_{S}\right)} \\
& \varphi_{d}(k)=\int \varphi\left(t_{k+1}, \tau\right) G(\tau) Q(\tau) G(\tau)^{T} \varphi^{T}\left(t_{k+1}, \tau\right) d \tau \\
& F[k]=\left.\frac{\partial f[x(t), u(t), t]}{\partial x}\right|_{x=\hat{x}_{k / k}}
\end{aligned}
$$

\subsection{Kalman Gain Matrix}

$$
\begin{aligned}
& K_{k+1}=P_{k+1 / k} H_{k+1}^{T}\left[H_{k+1} P_{k+\frac{1}{k}} H_{k+1}^{T}+R_{k+1}\right]^{-1} \\
& H_{k+1}=\left.\frac{\partial h[x(t), t]}{\partial x}\right|_{x=\hat{x}_{k+1 / k}}
\end{aligned}
$$

\subsection{Update the Covariance Matrix of States}

$$
P_{(k+1) /(k+1)}=\left[I-K_{k+1} H_{k+1}\right] P_{k+1 / k}
$$

\subsection{Update of the State Estimation}

$$
\hat{x}_{(k+1) /(k+1)}=\hat{x}_{k+1 / k}+K_{k+1}\left\{y_{k+1}-h\left[\hat{x}_{k+1 / k}, k+1\right]\right\}
$$

The process and the measurement noise vectors are random variables and characterized by: 
$E\{w(k)\}=0, E\left\{w(k) w(j)^{T}\right\}=Q \delta_{k j} ; Q \geq 0$

$E\{v(k)\}=0, E\left\{v(k) v(j)^{T}\right\}=R \delta_{k j} ; R \geq 0$

The initial state $\mathrm{x}(0)$ is characterized by:

$$
E\{x(0)\}=x_{0}, E\left\{\left(x(0)-x_{0}\right)\left(x(0)-x_{0}\right)^{T}\right\}=P_{0}
$$

\section{STATOR RESISTANCE ESTIMATION}

In general, the stator resistance is variable and the model deduced from vector spatial equations in $\mathrm{d}$ and $q$ coordinates, rotating with electrical angular velocity $\omega_{\mathrm{r}}$ is non-linear and time varying. The main idea of the MRAS is to compare the outputs of the two models and to adjust the value of Rs in order to minimize the result error. The adjustment value is the stator resistance generated from the error between measured and estimated stator currents. The error between the states of the two models is used to drive a suitable adaptation mechanism that generates the estimate $\widehat{\mathrm{R}}_{\mathrm{s}}$ for the adjustable model. Let us compute the state error components from.

$$
\left\{\begin{array}{l}
\varepsilon d=i d-\hat{i} d \\
\varepsilon q=i q-\hat{i} q
\end{array}\right.
$$

Using (25), the error of state equation is as follow:

$$
\left[\begin{array}{c}
\frac{d \varepsilon d}{d t} \\
\frac{d \varepsilon q}{d t}
\end{array}\right]=\left[\begin{array}{cc}
-\frac{R s}{L d} & \hat{\omega} r \frac{L q}{L d} \\
-\hat{\omega} r \frac{L d}{L q} & -\frac{R s}{L q}
\end{array}\right]\left[\begin{array}{l}
\varepsilon d \\
\varepsilon q
\end{array}\right]+\left[\begin{array}{r}
-\frac{i d}{L d} \\
-\frac{i q}{L q}
\end{array}\right](R s-\hat{R} s)
$$

Equation (30) can be written in state error model representation as:

$$
p[\varepsilon]=[A 1][\varepsilon]+[W 1]
$$

where $\varepsilon=\left[\begin{array}{ll}\varepsilon d & \varepsilon q\end{array}\right]^{T}$ is the error state vector, $[A 1]$ is the state matrix and $[W 1]$ is the feedback block defined as:

$$
[A 1]=\left[\begin{array}{cc}
-\frac{R s}{L d} & \hat{\omega} r \frac{L q}{L d} \\
-\hat{\omega} r \frac{L d}{L q} & -\frac{R s}{L q}
\end{array}\right],[W 1]=\left[\begin{array}{c}
-\frac{i d}{L d} \\
-\frac{i q}{L q}
\end{array}\right](R s-\hat{R} s)
$$

The term of $[W 1]$ is the input and $[\varepsilon]$ is the output of the linear feed forward block and it can be easily shown that the linear equivalent system will be completely observable and controllable. The former state equation (31) describe the equivalent MRAS in a linear way as it was previously specified and $[\varepsilon]$ is the main information upon which differences existing between the adjustable model and the reference model. The asymptotic behavior of the adaptation mechanism is achieved by the simplified condition $[\varepsilon(\infty)]^{T}=0$ 
for any initialization. The feedback system will be hyperstable for any feedback block of the class satisfying the inequality:

$$
\int_{0}^{t 0}[\varepsilon]^{T}[W 1] d t \geq-\gamma^{2} \text {. for all } t 0 \geq 0
$$

Where $\gamma 1$ is a finite positive real constant, which is independent of $t 0$ The necessary and sufficient condition for the feedback system to be hyperstable is as follow, The transfer function of the feed forward linear time invariant block $H 1(p)=(p[I]-[A 1])^{-1}$ must be a strictly positive real transfer matrix and the nonlinear time varying block satisfies the Popov's integral inequality. From the previous equation (32) and the Popov's inequality, it can be easily show that the observed stator resistance satisfies this relationship:

$$
\hat{R} s=A 1([\varepsilon])+\frac{1}{p} A 2([\varepsilon])
$$

With:

$$
\begin{aligned}
& A 1([\varepsilon])=-K 1\left(\frac{1}{L d} i d \varepsilon d+\frac{1}{L q} i q \varepsilon q\right) \\
& A 1([\varepsilon])=-K 1\left(\frac{1}{L d} i d \varepsilon d+\frac{1}{L q} i q \varepsilon q\right)
\end{aligned}
$$

In Equation (34) and (35), K1 and K2 are the positive adaptation gains by means the stator resistance which can be adjusted. Based on adaptive control theory, the state error $[\varepsilon]$ can be tending to zero by means of parameters adjustable model using adaptive laws when the system is stable. The meaning is to feed this error signal to polarization-index (PI)-type controllers to estimate adaptively the unknown stator resistance. So, the adaptive law of stator resistance is written as:

$$
\hat{R} s=K R s i-e s t \int_{0}^{t}\left(\frac{1}{L d} i d \varepsilon d+\frac{1}{L q} i q \varepsilon q\right) d t-K R s p-e s t\left(\frac{1}{L d} i d \varepsilon d+\frac{1}{L q} i q \varepsilon q\right)+\hat{R} s(0)
$$

where KRsi-est and KRsp-est are the PI stator resistance, observer controller and $\hat{R}_{s}(0)$ is the initial value of $\hat{R} s$

\section{FAULT TOLERANT DRIVE TOPOLOGY}

Various fault tolerant inverter topologies have been proposed in the literature. The failures that may involve the inverter power stage can take place either in the switches of the inverter or in their gate command circuitry. They are many faulty situations such as: open circuit of both power devices of an inverter leg, short circuit of both power devices of an inverter leg, short circuit of one power device and open circuit of one power device. In this paper we considered only the short circuit of one power device case Figure 1.

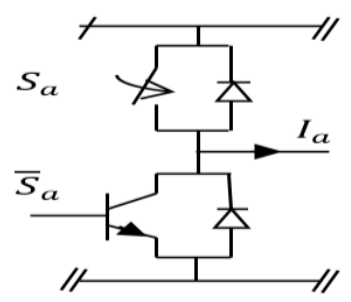

Figure 1. Single switch short-circuit inverter fault 


\subsection{Simple Switch short circuit Fault Detection Method}

The switching devices of the voltage source inverter have the electrical and thermal stresses due to the high voltages and currents in the PMSM drive. Furthermore, the high switching frequency by the pulse width modulation (PWM) gives more stresses on the switching devices. The probability of the troubles which could happen in the switching devices is quite high as compared with the other components of the drive system. The proposed method used for detects the switch short circuit is based on the analysis of the mean value of the stator currents.

\subsection{Fault tolerant inverter principle}

The ability to isolate a faulty phase leg opens the possibility of introducing a spare inverter leg for improved fault tolerance as shown in Figure 2. The configuration will be referred to as the phase redundant topology. This circuit topology incorporates isolating THs and fuses in only three active legs of the inverter [18], [19], [20]. A spare fourth leg of the inverter is connected in place of the faulty phase-leg after the fault isolating devices have removed that that leg from the system. During normal operation, this spare phase leg is inactive. As result, the three TRIACs shown in the topology act as static transfer switches to connect this output to the faulted phase only when needed.

\section{RECONFIGURATION STRATEGY}

The following scheme, Figure 3 shows the principle of the control software that's developed to study the system.

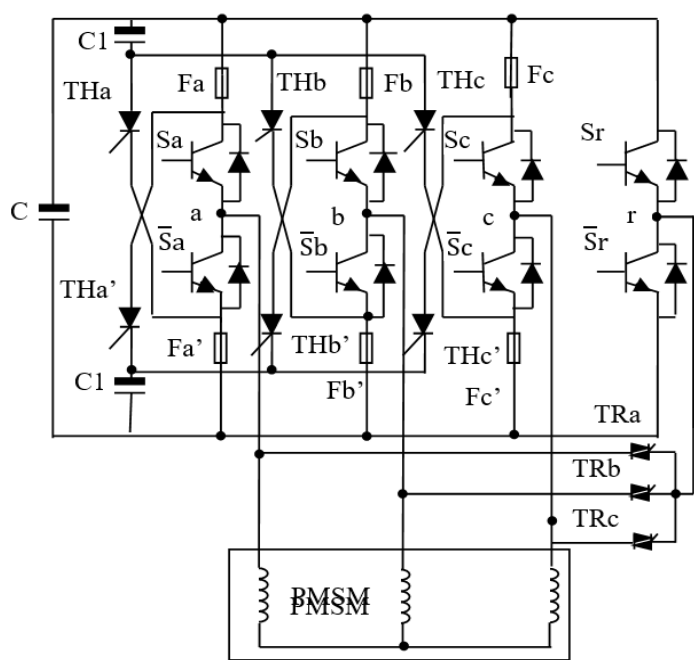

Figure 2. Phase redundant topology

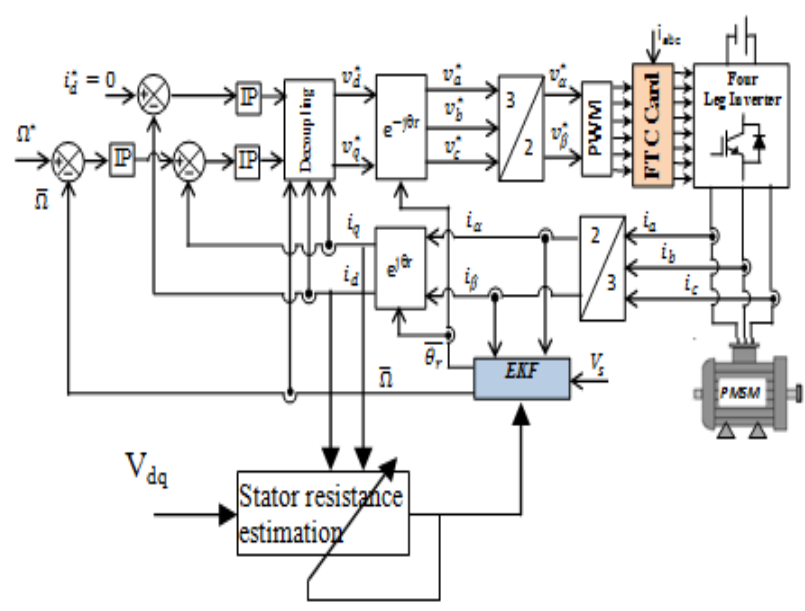

Figure 3. Reconfiguration scheme

\section{FAULT DETECTION AND ISOLATION}

Figure 4 shows the block diagram of the FDI method where moving window rms value of each phase current is calculated first and then two currents are subtract from each other. In healthy operation currents are balance hence they have nearly equal rms values. Therefore, the subtraction will produce only a small residue. However during the faulty mode only the faulty phase current become zero while the healthy phase have increased magnitudes. Hence, output of two subtract blocks show large residue. However, only one phase current shows positive residue hence this can be used to detect and identify the fault. The generated residue can be normalized to help the setting of realistic and fixed threshold value for detecting the fault. redundant

For example if $\mathrm{F} \_\mathrm{a}=1$, there will be switching of the control signals from the leg A to that of the 


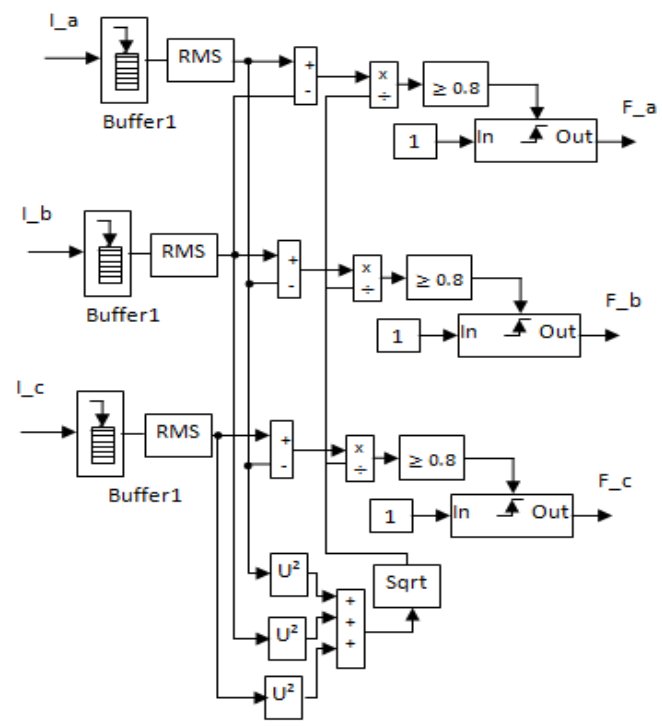

Figure 4. Fault detection block

\section{SIMULATION RESULTS}

\subsection{Simulation results for IGBT short circuit fault:}

A simulation model has been developed for testing the fault tolerant PMSM Drive. Results are produced for healthy mode, faulty mode and tolerant inverter's response to a fault case.

Figure 5 shows the currents, Electromagnetic Torque and Mechanical speed responses of the PMSM in healthy mode case.
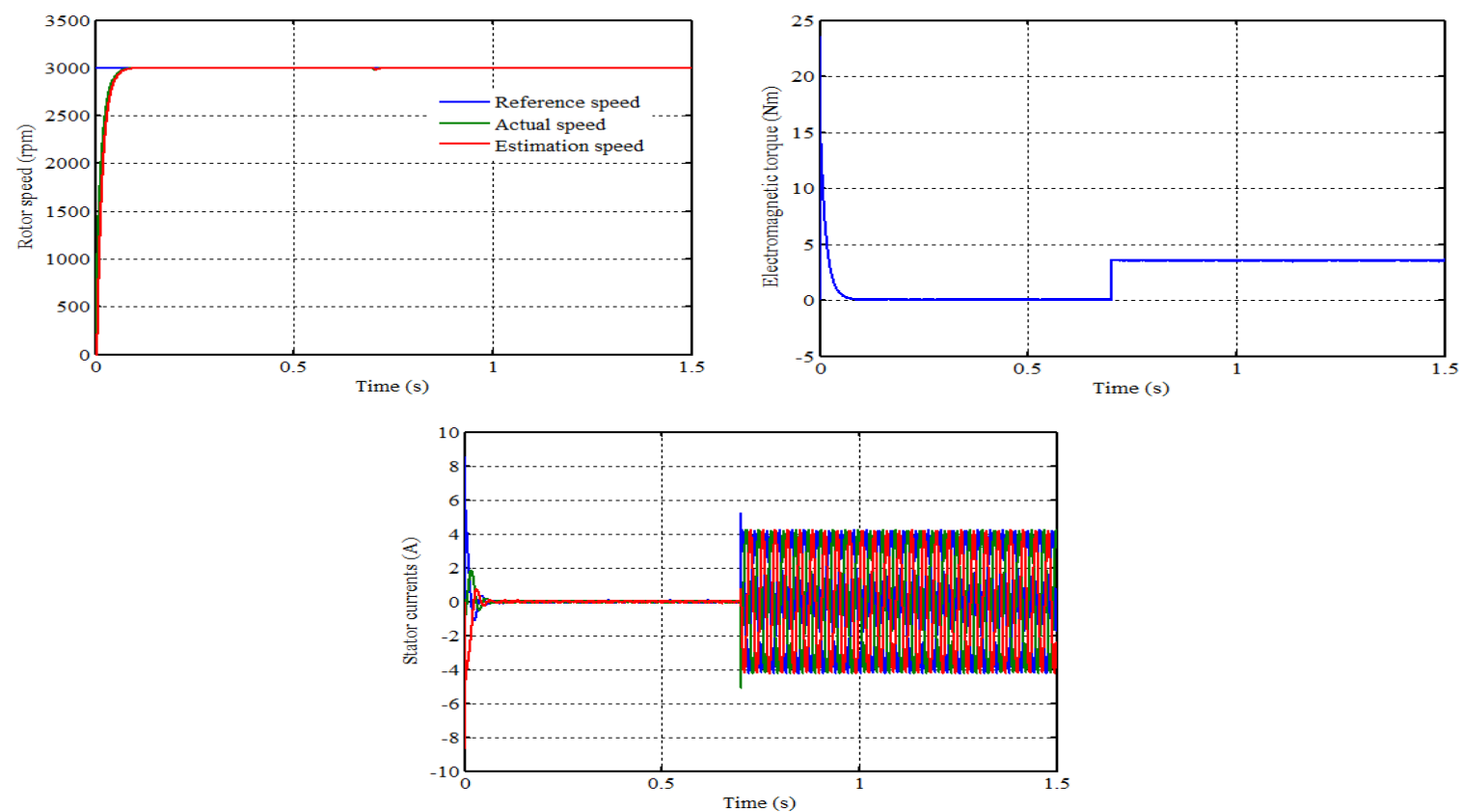

Figure 5. Rotor speed, EM-torque and stator currents response healthy mode case

As a first test, Figure 5 shows a typical start-up of the PMSM without fault. The reference rotor speed is set at $3000 \mathrm{rpm}$ with step nominal load torque $\mathrm{Tl}=4 \mathrm{Nm}$ applied to the system at time $\mathrm{t}=0.7 \mathrm{~s}$. Figure 
6 shows that the speed drop at the time of applying a load torque does not exceed $4 \%$, while the duration of the disturbance does not exceed $0.5 \mathrm{~s}$.

The following Figure 6 shows the currents, Electromagnetic Torque and Mechanical speed responses of the PMSM in faulty mode case.
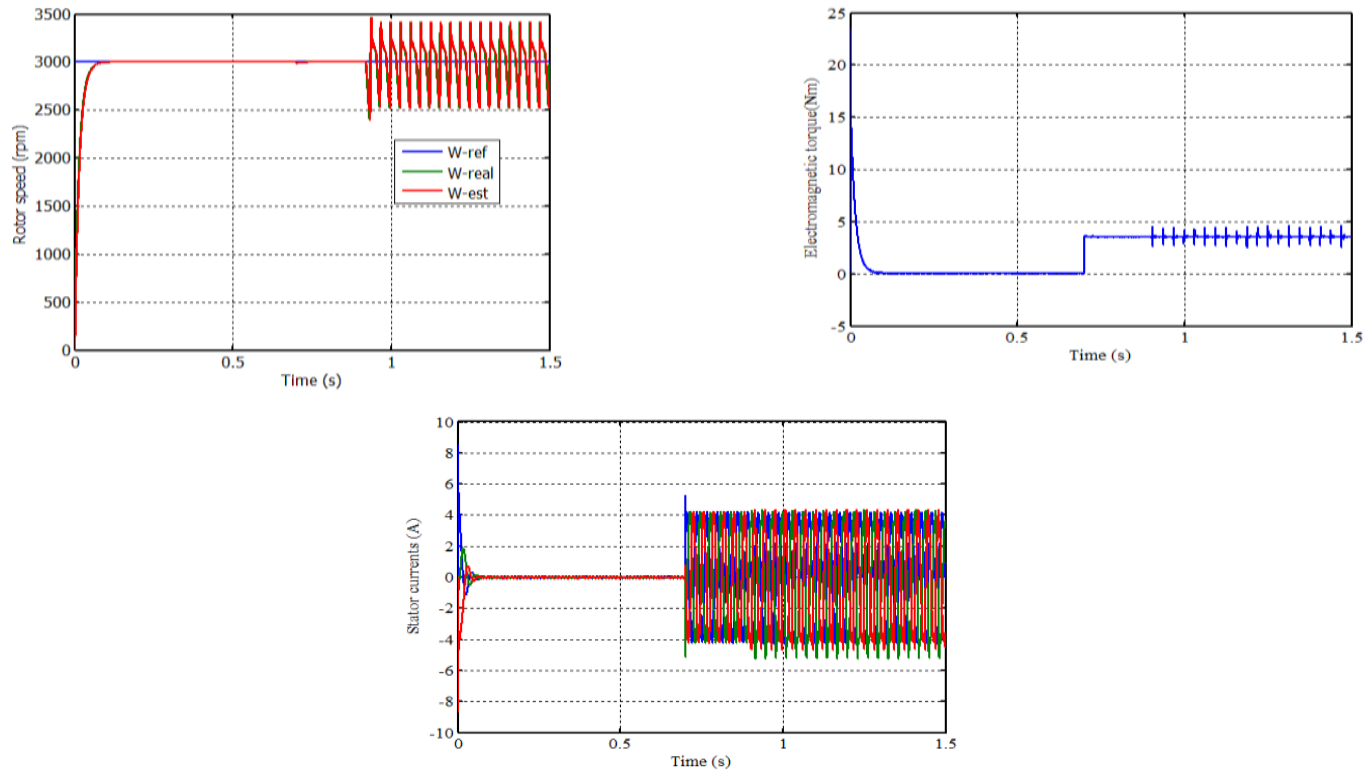

Figure 6. Rotor speed, EM-torque and stator currents response faulty mode switch short circuit case

A short circuit fault is created by turning on of the IGBT gate signals permanently ON. In our case of fault detecting time is evaluated about " $0.05 \mathrm{~s}$ ". Figure 7 shows the Electromagnetic torque, stator currents, and mechanical speed responses of the PMSM to a short circuit fault in the upper IGBT of phase A.
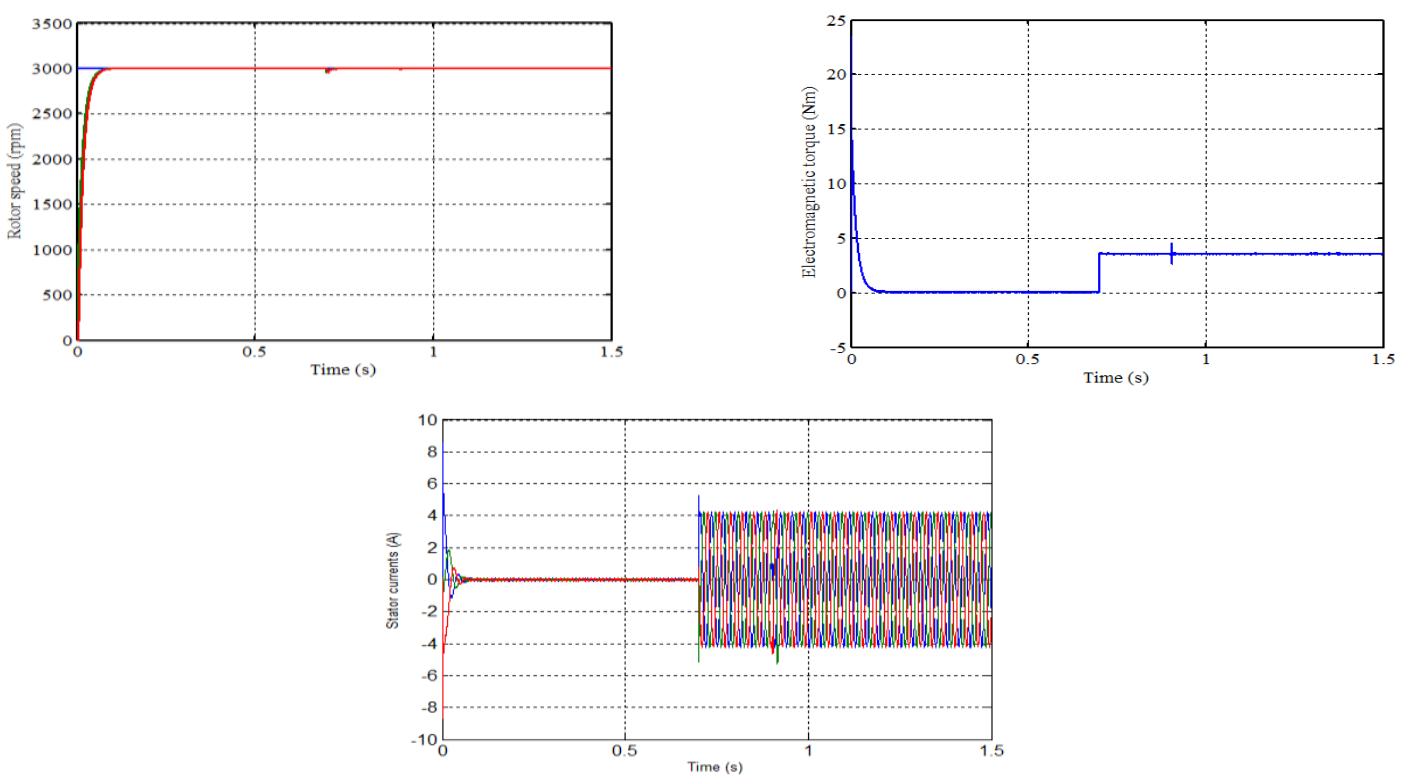

Figure 7. Rotor speed, EM-torque and stator currents response tolerant inverter's case 
After having shown that the system does not able to function in case of a failure, this section shows results of the inverter reconfiguration. The machine starts rotating at $t=0$ and a short circuit is created on the first leg upper switch at $\mathrm{t}=0.9 \mathrm{~s}$.

The reconfiguration is executed after that the fault is detected and the faulty leg is isolated. The gate signals of the faulted leg are stopped and the new gate signals of the fourth leg are applied.

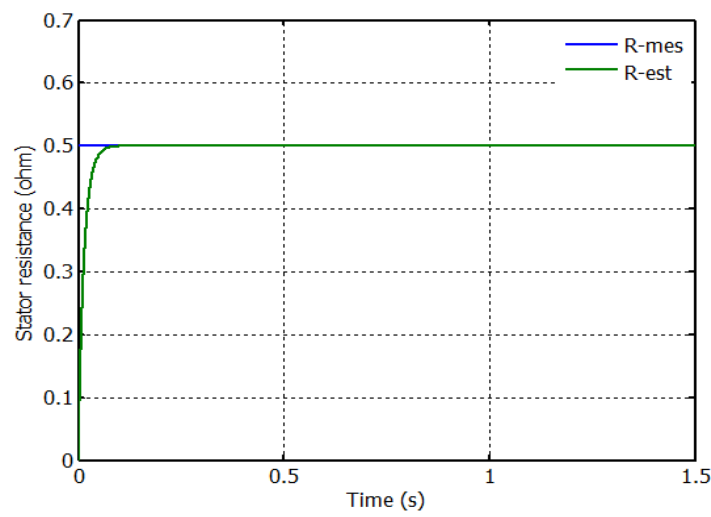

Figure 8. Real and estimated resistance

Figure 8 shows that the estimated resistance converges towards the actual resistance, hence the effectiveness of the proposed method.

\section{CONCLUSION}

This paper proposes an inverter fault tolerant sensorless control FOC scheme using extended Kalman filter for a PMSM drive system with stator resistance estimation. A fault tolerant witch-redundant inverter, which has the same function as the standard 6-switch 3-phase inverter, has been introduced; which could be reconfigured to a 4-switch 3-phase inverter or 4-switch 2-phase inverter after a short circuit in the upper switch phase A. These two 4-switch inverters can only produce four non-zero voltage vectors with different amplitude, and could not offer the full voltage as in the standard inverter fed system. A FOC strategy was obtained based on the detailed analysis of these 4-switch inverters. Several simulation results have

\section{REFERENCES}

[1] R. Errabelli, P. Mutscher, "Fault tolerant voltage source inverter permanent magnet drives," IEEE copyright $($, 2011.

[2] Rakesh Ghanshyamlal Shriwastava, M.B. Diagavane, S.R. Vaishnav"Literature Review of Permanent Magnet AC Motors and Drive for Automotive Application. Electrical Engineering and Informatics (BEEI), vol.1, №1:2012

[3] Reza Ilka, S. Asghar Gholamian,"Optimum Design of Five-phase Permanent Magnet Synchronous Motor for Under water Vehicles by use of Particule Swam Optimization",Telecommunication, Computing, Electronics and Control (TELKOMNIKA), vol.10, N4:2012.

[4] F. Genduso, R. Miceli, C. Rando, G.R. Galluzzzo,"Back EMF sensorless-control algorithm for high-dynamic performance PMSM,” IEEE Trans. Ind. Electron., vol. 57, no. 6, pp. 2092-2100. May 2009.

[5] Y. Shi, K. Sun, L. Huang, Y. Li, "On-line identification of permanent magnet flux based on extended Kalman filter for IPMSM drive with position sensorless control,” IEEE Trans. Ind. Electron., 2012.

[6] Chien-Feng Wu, Shir -Kuan Lin. "A Novel Sensorless Initial Rotor Position Estimation Method for Permanent Magnet Synchronous Motors” International journal of power electronics and drive systems (IJPEDS), vol $8 \mathrm{~N}^{\circ} 1$, 2017.

[7] G.S. Buja, M.P. Kazmierkowski, "Direct torque control of PWM inverter-fed Ac motors-A survery, " IEEE Trans. Ind. Electron., vol.51, no.4,pp.744-757, 2004.

[8] Mini R, Saranya C, B. Hariram Satheesh, Dinesh M.N.’Low Speed Estimation in Sensorless Direct Torque Controlled Induction Motor Drive Using Extended Kalman Filter" International journal of power electronics and drive systems (IJPEDS), vol $6 \mathrm{~N}^{\circ} 4,2015$.

[9] R. Correa, B. Jacobina, C. daSilva, A. Lima, “An induction motor drive system with iproved fault tolerance,” IEEE Trans. On industry applications, vol.37, no.3, 2001. 
[10] J. Guitard, F. Richard, K. Bouallaga, "Fault tolerant inverter with real time monitoring for aerospace applications,"IEEE 14th international power electronics and motion control conference, EPE-PEMC 2010.

[11] M. Azab, Al. Orille, "Novel flux and torque control of induction motor drive using four switch three phase inverter, "IEEE industrial electronics society conference, pp.1268-1273, 2001.

[12] I.Bahri, I.S. belkhoja, M. Eric, "FPGA based real time simulation of fault tolerant current controllers for power electronics," IEEE international symposium on industrial electronics ISIE, 20009.

[13] N. Ertugrul, W. Soong, G. Dostal, D. saxon, "Fault tolerant motor drive system with redundancy for critical applications,"Proc. Power electron.spec. conf., vol.3 pp.1457-1462, 2002.

[14] F. Meinguet, J. Gyselinck, "Control strategies and reconfiguration of four leg inverter PMSM drives in case of single phase open circuit faults, "IEEE, 978-1-4244-4252-2,2009.

[15] S.J Underwood, I Hussain, “Online parameter estimation and adaptive control of PMSM,'IEEE Trans.Ind. Electron., vol. 57, no, 7, pp. 2435-2443, 2010.

[16] A. Khlaief, M. Bendjedia, M. Boussak, A. Châari,’'Nonlinear Observer for sensorless Speed Control og IPMSM Drive with Stator Adaptation,"2nd Conference on communications, computing and control applications ,2012.

[17] M. Boussak, "Implementation and experimental investigation of sensorless speed control with initial rotor position estimation for interior permanent magnet synchronous motor drive, "IEEE trans. On power elect., vol.20, no.6, pp.1413-1422, 2005.

[18] M. Moujahed, H. Benazza, M. Jemli, M. Boussak, "Speed estimation by using EKF techniques for sensorless DTC for PMSM with load torque observer, ” IREE, vol.9 no 2, 2014.

[19] Mohammad Jannati, Tole Sutikno, Nik Rumzi Nik Idris, Mohd Junaidi Abdul Aziz,” High Performance Vector Control of 3-Phase IM Drives under Open-Phase Fault Based on EKF for Rotor Flux Estimation",International journal of Electrical and computer Engineering (IJECE), vol 6, $\mathrm{N}^{\circ}$ 2: 2016

[20] S. Bolognani, M. Zordan, M. Zigliotto, "Experimental fault tolerant control of a PMSM drive, "IEEE trans. Ind. Electronics, vol.47, pp.1134-1141, 2000. 